\title{
Dance, communication and schizophrenia
}

\author{
Josephine Loftus
}

\begin{abstract}
"Dancing possesses all the features of a beautiful language, yet it is not sufficient to know the alphabet alone. But when a man of genius arranges the letters to form words and connects the words to form sentences, it will cease to be dumb, it will speak with both strength and energy; and the ballets will share with the best plays the merits of affecting and moving"
\end{abstract}

(Noverre, 1760: cited in Copeland \& Cohen, 1983. p. 290)

"I should like to emphasise that some of the clinical pictures outlined are no more than attempts to present part of the material observed in a communicable form"

(Kraepelin, 1920;

cited in Hafner et al, 1987, pp. 29-38)

At the time of Nijinsky's birth in 1889 , ballet was still awaiting the 'man of genius' who would realise its full potential as a self-sufficient form of expression. Psychiatry was still grappling with the various faces of madness in an attempt to establish a universally comprehensible language. By 1889 the term psychosis (originally meaning animation of the soul), coined 40 years earlier (Beers, 1995b), was beginning to assume the meaning which psychiatry attributes to it today. Kraepelin was about to formulate his concept of the psychoses which were so tragically to cut short Nijinsky's career both as performer and choreographer.

Born into a family of ballet dancers, Nijinsky learned to express himself at an early age through the medium of dance and by the age of four had made his first public appearance. During this period, Kraepelin was building on the concepts of Kahlbaum and by 1896 had formulated his concept of dementia praecox as a diagnostic entity. Based on his observation of outcome, he distinguished it from the affective disorders and thus established a dichotomy in the psychoses which has influenced psychiatry to the present day. Kraepelin was a materialist who believed that mental illness was a disease of the brain and that dementia praecox was a disease process for which a cause would eventually be found. This reductionist approach was being challenged by people such as Freud whose secular approach to problems of the psyche superseded that of the mentalists in the previous century.

Meanwhile, Nijinsky, now eight years old was enrolled in the Imperial School of Ballet in St Petersburg. His exceptional talent was soon recognised and compensated for his hyperactive behaviour, social gaucheness and poor verbal skills in gaining recognition in this prestigious establishment. Elsewhere, the world of dance was being subject to the same influences as art. music and literature. These included a revival of interest in antiquity, enthusiasm for primitive art and an increasing preoccupation with the psyche. The effect on Western Art was to change the emphasis from style, decor and narrative to expressing the subjective experience of the individual. The renewed interest in the psyche was to have an impact through Freud and Jung on Bleuler's concept of dementia praecox. Although Bleuler accepted that there was an organic basis to the illness, he believed that there was a psychological explanation for the more prominent symptoms. The neologism 'schizophrenia' was coined by him to illustrate his broader concept of the illness (Bleuler, 1911).

While Bleuler was attempting to put the psyche back into insanity. Nijinsky was about to graduate from the Imperial School of Ballet. Only 18 years old, he already had a role in a new ballet created especially for him and was in demand as a partner for famous ballerinas. Through his meeting with Diaghilev, his lover and mentor, he was exposed to the revolutionary trends in Western Art and was anxious to incorporate these trends into dance. As the term schizophrenia began to enter common parlance, Nijinsky, who was later on occasions to embody the concept, was about to receive both accolades and disapprobation from Parisian critics and audiences for his revolutionary choreography.

Paradoxically for someone renowned for his lack of verbal fluency, he was hailed by artists of his day for his "extraordinary ability to lend his body to the interpretation of the widest possible range of feelings." (Rodin, 1912; cited in Nectoux 1990). Elsewhere he was described as the author of a poem in choreography (von Hofmannsthal, 1912; cited in Nectoux 1990, pp. 52-53.) This 
begs the question as to what was so unique about Nijinsky's choreography. The process of revolutionising dance had already been initiated by Isadora Duncan and Michel Fokine who explored its expressive nature. Nijinsky was to develop this to its extreme. Jacques Rivière, in 1913, (cited in Copeland \& Cohen, 1983, pp. 115-123) wrote the following on seeing The Rites of Spring

"With what eloquence he curled himself like a cat around emotions. How he hovered over them closely. How well he knew how to arrange all his limbs in their image and make himself their effigy... we are able to contemplate them before the arrival of language before they are pressed upon by multitudinous and subtly varied but loquacious crowds of words... What beauty lies behind this reduced and dislocated dance?"

Nijinsky instinctively believed that movement was an adequate and effective means of communication. In his ballets, he acknowledged this by refusing to create an illusion of reality on stage. By relinquishing excessive reliance on stage decor, mimicry or pantomime and proceeding to banish all facial expression, he reduced dance to its essential component - movement. In L'Après Midi d'un Faune, the dancers moved laterally across the stage in jerky movements, their bodies facing the audience while their feet and heads were turned sideways like figures on an ancient Greek vase (which Nijinsky used for inspiration) suddenly and awkwardly come to life but remaining distant and inaccessible. Nijinsky is said to have created a fourth wall, taken at that time for granted in theatre but underdeveloped in the world of ballet because of its lack of faith in itself as a mediator of human experience. An abstract visual spectacle was presented. What was real was the emotional reaction and interpretation of each individual in the audience. It was like someone expecting to attend an exhibition of the old masters suddenly being accosted by the cubist works of Picasso with the exception that the world of art was more prepared for such innovation than the world of ballet in 1912.

Nijinsky stripped away the aesthetic in order to express the emotional, social and primitive nature of man. It is tempting to speculate that he compensated for his verbal and social awkwardness by using dance as his primary mode of expression, so that he was well placed in later years to develop dance as a sophisticated independent form of artistic expression. In doing so, he became an exponent of the expression theory of art which views all art as a valid form of linguistic expression (Collingwood, 1938; cited in Copeland \& Cohen, 1983, pp. 371-376). Communication was extremely important to Nijinsky. He wrote extensively in his diary about his feelings, made several abstract drawings and when unable to perform, demonstrated his ballets to family members.

The years following Nijinsky's triumph in Paris were eventful. There was his sudden marriage which precipitated his rupture with Diaghilev, followed by fatherhood, his first encounter with depression from which he recovered and the First World War. It was towards the end of the war that Nijinsky's world began to disintegrate. He attempted to convey this in a private performance in St Moritz in 1919 but the form was too abstract for his audience who may well have considered it further confirmation of his descent into insanity. Despair, grandiosity, lack of comprehension coupled with piercing insight are evident in his diaries. In the early stages of his descent into madness, Nijinsky (1973) expressed the fear that he was losing his feelings and protested against the intellectualisation of his mind. Elsewhere he wrote "I want light, the light of twinkling stars. A twinkling star is life and a star that does not twinkle is death." This has been interpreted as Nijinsky expressing his sense of loss at no longer being able to perform on stage (Oswald, 1991) but could also have reflected insight into his loss of emotions and ability to feel. He described himself as "sick in my soul but not in my brain", inadvertently echoing the debate that divided psychiatrists for decades. For Nijinsky, madness was dehumanising perhaps because it deprived him of his own natural language which had permitted people to penetrate his boorish exterior and see a wealth of emotion, sensitivity and intelligence. Having experienced the alienation of the misunderstood genius, Nijinsky was now to experience the double alienation of being insane and isolated from his natural and most effective mode of selfexpression. His frustration must have been compounded by his inability to realise the many ballet projects festering in his disorganised mind.

Nijinsky was to receive several diagnoses throughout his life. These included dancer's heart, neurasthenia, dementia praecox, schizophrenia and depression. The confusing nature of his symptoms is evident on Bleuler's first meeting with Nijinsky when he pronounced him as suffering from "confused schizophrenia with mild manic symptoms" (Oswald, 1991). No longer allowed to perform phenomenal leaps on stage, Nijinsky was now confined to hurtling himself over the Kraepelinian boundaries dividing the psychoses. The incapacitating nature of his illness, disorganisation of speech and behaviour, disturbance of affect and catatonic symptoms would have satisfied the criteria of both Bleuler and Kraepelin while his extremes of mood would have perplexed them, particularly Kraepelin. The presence of first rank symptoms would have been reassuring to Schneider in 
making a diagnosis of schizophrenia although the latter's concept of psychosis as being qualitatively distinct from the norm and due to some inherent or congenital defect (Beer, 1995a) would nearly cost Nijinsky his life in Nazi occupied Hungary during the Second World War. Just as his art was susceptible to other influences in society, so was the concept and treatment of his illness influenced by the prevailing theories and philosophies of the day.

At Bellevue in Switzerland, he was under the care of Ludwig Binswanger, who influenced by Freud, was interested in psychoanalysis. There was considerable interest in Jaspers' phenomenological approach to psychiatric symptoms with its emphasis on making sense out of the patient's experience. He also met with Adler, who was later to write that "Nijinsky's spiritual death has aroused the sympathy of a great proportion of the civilised world" (Adler, 1981). Due to practical difficulties, Adler was unable to apply his methods to Nijinsky's case. At the other extreme, he underwent 180 treatments of insulin shock treatment under the supervision of its pioneer, Dr Manfred Sakel. This produced a temporary improvement in affective reactivity and was also credited with freeing him from hallucinations but he suffered linguistic dysfunction which degenerated into word salad. Bleuler's initial impression was that Nijinsky's prognosis was reasonably good provided that he was relieved of his family responsibilities and allowed to pursue his artistic instincts, hence Bleuler's unwelcome advice on divorce to Nijinsky's wife. The range of treatments reflect the divergent views of the illness as either psychogenic or organic in origin. A difficult, sometimes violent patient, Nijinsky subsequently became more manageable and spent the last few years of his life after the Second World War with his wife in England.

The renowned and inspirational dancer died in London in April 1950, the year The First International Conference of Psychiatry was held at which Adolf Meyer (Hafner et al, 1987, pp. 2938) exclaimed that psychiatrists were in danger of no longer understanding each other when they spoke about schizophrenia. Although Nijinsky's last major public performance was 33 years earlier, he remained a legend. His most signifi- cant contribution was his success in realising Noverre's vision of dance. Meyer's pessimistic appraisal in 1950 would have disheartened Kraepelin who thought he had devised a comprehensible diagnostic language for psychiatry. Nevertheless, his concepts have persisted and are evident in contemporary criteria. Nijinsky was reductionistic in his choreography in order to lay bare the emotional and instinctual nature of man, to animate the psyche and give it voice through the medium of movement. Kraepelin was also a reductionist but in the opposite direction in that he saw the soul or psyche as having little to do with dementia praecox, a neuropathological disease entity. Their paths converged in the psychoses where the psyche of one endured the torment and was stifled by the psychoses so eloquently described by the other.

\section{Acknowledgement}

I thank Dr Roisin Kemp for her helpful comments.

\section{References}

ADLER, A. (1981) The preface to The Diary of Vaslaw Nijinsky, Archives of General Psychiatry, 38, 834-835.

BEERS, M. D. (1995a) The importance of the social and intellectual contexts in a discussion of the history of the concept of psychosis. Psychological Medicine, 26, 317321

- (1995b) Psychosis: from mental disorder to disease concept. History of Psychiatry. 6. 177-200.

Bleuler, E. (1911) Dementia Praecox or the Group of Schizophrenias (trans. J. Zinkin. 1950). New York: International Universities Press.

COPELAND, R. \& COHEN, M. (eds) (1983) What is Dance? New York: Oxford University Press.

HAFNER, H., GatTaZ, W. F. \& JANZaRIK, W. (eds) (1987) Search for the Causes of Schizophrenia. New York Springer-Verlag.

NiJINSKY, V. (1973) The Diary of Vaslav Nijinsky (trans./ed. R. Nijinsky). Berkeley. CA: University of California Press.

Oswald, P. (1991) Vaslav Nijinsky: A Leap into Madness, p. 229. London: Robson Books Ltd.

Nectoux. J. M. (ed.) (1990) Prelude A L'Après-Midi D'un Faune. London: Thames and Hudson.

Josephine Loftus, Specialist Registrar, Community Psychiatric Rehabilitation Team, 5052 Clifden Road, London, E5 OLJ 